\title{
Effects of zebra mussels on a native amphipod and the invasive Dikerogammarus villosus: the influence of biodeposition and structural complexity
}

\author{
René Gergs ${ }^{1}$ AND Karl-Otto Rothhaupt ${ }^{2}$ \\ Limnological Institute, University of Konstanz, D-78467 Konstanz, Germany
}

\begin{abstract}
In the last decades, zebra mussels (Dreissena polymorpha) have invaded many freshwater systems with severe consequences for entire communities. Most benthic macroinvertebrates, especially amphipods and chironomids, increase in abundance in the presence of zebra mussels. Increased structural complexity and an unknown biotic factor lead to this effect. Dreissena-associated factors that might influence populations of the native Gammarus roeselii and the invader Dikerogammarus villosus in Lake Constance, Central Europe, were investigated in laboratory experiments. These factors were: 1) increased structural complexity related to mussel shells, 2) Dreissena biodeposition, 3) chironomids, the presence of which is increased by biodeposited matter, and 4) Dreissena kairomones. In habitat-choice experiments, the native and omnivorous amphipod $G$. roeselii showed a preference for mussel shells with biodeposited material and for mussel shells with biodeposited material with chironomids, whereas the invasive and predatory amphipod D. villosus showed a preference only for mussel shells with biodeposited material with chironomids. In a kairomone y-maze experiment, both amphipods avoided zebra-mussel-conditioned lake water. These results indicate that habitat complexity and food availability, mediated directly or indirectly through biodeposited material, are the factors by which amphipod abundances are increased in the presence of Dreissena. Thus, biodeposited material can form an important new food resource, translocated from the pelagic zone to the benthos by zebra mussel filtration, and this biodeposited material might support a new detritus-based food web in the benthos.
\end{abstract}

Key words: biodeposition, zebra mussel, food web, Gammarus roeselii, Dikerogammarus villosus, habitatchoice, kairomone, preference.

Zebra mussel invasions in Europe and North America have led to many changes in planktonic and benthic communities in invaded habitats (Stanczykowska et al. 1976, Griffiths 1993, Roditi et al. 1997, Mörtl and Rothhaupt 2003). Filtration by mussels reduces the overall concentration of phytoplankton (e.g., Holland 1993, Nicholls and Hopkins 1993) and alters the makeup of the phytoplankton community. The reduction in phytoplankton leads to higher light levels, which in turn, lead to the proliferation of submersed macrophytes (Skubinna et al. 1995).

Abundances of many benthic taxa, especially amphipods and chironomids, increase in response to zebra mussel invasion (Stewart and Haynes 1994, Mörtl and Rothhaupt 2003). Zebra mussels alter the benthic habitat by increasing the surface area and restructuring the substrate in the form of mussel shells.

\footnotetext{
${ }^{1}$ E-mail addresses: rene.gergs@uni-konstanz.de

2 karl.rothhaupt@uni-konstanz.de
}

The mussels also appear to influence the benthic community by biodeposition, causing an accumulation of pelagic resources in the benthos (Stewart and Haynes 1994, Silver Botts et al. 1996, Ricciardi et al. 1997, Stewart et al. 1998). Zebra mussel density is controlled through predation by diving ducks in some habitats: a reduction of $>90 \%$ of the zebra mussel density has been observed in Lake Constance during winter (Cleven and Frenzel 1993, Werner et al. 2005). Control of zebra mussel density by waterfowl increases seasonal variation of the habitat structure and the amount, and therefore, the importance of biodeposited matter.

The omnivorous amphipod Gammarus roeselii (Bärlocher and Kendrick 1973, Pöckl 1992, 1993, Friberg and Jacobsen 1994) was the dominant species in the littoral zone of Lake Constance (Mörtl 2003) before the Ponto Caspian amphipod Dikerogammarus villosus invaded the lake in 2002 (Mürle et al. 2004). Presence 
of the predatory $D$. villosus has been correlated with decreases in abundances of other benthic species in other invaded ecosystems (Dick and Platvoet 2000, Dick et al. 2002). Thus, post- $D$. villosus-invasion decreases in abundances of many benthic species are expected in Lake Constance.

Biodeposition by zebra mussels could lead to the development of a biodeposit-based food web (Stewart and Haynes 1994, Mitchell et al. 1996). Macroinvertebrates can benefit from this resource directly by feeding on biodeposited material or indirectly by predation on other macroinvertebrates. Detritivorous chironomids, the abundances of which increase after zebra mussel invasions (Stewart and Haynes 1994, Mörtl and Rothhaupt 2003), might be a link to higher trophic levels. Zebra mussels also might influence the benthic community through kairomones, which might cause an increase in abundance of the olfactorysensitive amphipods (Wudkevich et al. 1997, Baumgärtner et al. 2002). A kairomone-based response would result in redistribution of amphipods in the habitat rather than an increase in total amphipod abundance.

We hypothesized that either the availability of additional food from biodeposition or zebra mussel kairomones are responsible for the increase in amphipod abundance near living zebra mussels. We tested these hypotheses by investigating the importance of biodeposited material, living chironomids, and kairomones produced by zebra mussels on the behavioral response of 2 amphipod species, the native and omnivorous $G$. roeselii and the invasive and predatory $D$. villosus. These results could help to elucidate the importance of zebra mussel biodeposition for the benthic food web of lake littoral zones (Walz 1978).

\section{Methods}

\section{Origin and maintenance of the animals}

The amphipod species G. roeselii and D. villosus, living zebra mussels, and mussel shells were obtained from the littoral zone of the prealpine and oligotrophic Lake Constance (Central Europe, on the border of Germany, Switzerland, and Austria). Water levels fluctuate annually within $2 \mathrm{~m}$, depending largely on the unregulated alpine system of the Rhine River. The main basin of Lake Constance has a mean depth of 100 $\mathrm{m}$ and covers $473 \mathrm{~km}^{2}$ (IGKB 2004).

In the laboratory, the 2 amphipod species and the zebra mussels were kept separately in a $15^{\circ} \mathrm{C}$ climate chamber with a diurnal light rhythm of $12 \mathrm{~h}: 12 \mathrm{~h}$ (day:night). Habitat-choice and y-maze experiments also were conducted in this climate chamber. Zebra mussels and G. roeselii were maintained in tanks filled with water from Lake Constance. Dikerogammarus villosus was kept in a flow-through system with water from Lake Constance to minimize their mortality rate. Gravels of different grain sizes were provided for shelter for amphipods. Both amphipod species were fed commercially available frozen chironomids. In all experiments, only adult amphipods (0.7-1.7-mm length) of both sexes were used. Different amphipods were used in each replicate in both experiments.

\section{Habitat-choice experiment}

The attractiveness of food sources provided directly or indirectly by zebra mussels was examined in a 2chamber habitat-choice arena (Fig. 1). Each 9- $\times 9-\times 7$ $\mathrm{cm}$ chamber was constructed of gray polyvinyl chloride (PVC), and chambers were separated by a removable dividing wall $(3.5 \times 7 \mathrm{~cm})$. Each chamber featured a notch to hold an unglazed $4.7-\times 4.7-\mathrm{cm}$ tile. The reference habitat for all tests was a tile with 15 mussel shells attached to the tile with superglue (UHU plus 2-components epoxy resin glue; UHU, Bühl, Germany).

Five different habitat treatments were tested against the reference habitat: 1) tiles with mussel shells (reference habitat $=$ mussel shells), 2) bare tile, 3) tiles with living mussels (living mussels), 4) tiles with mussel shells and biodeposited material produced by zebra mussels (biodeposited material), and 5) tiles with mussel shells, biodeposited material, and 30 living chironomids (biodeposited material with chironomids). The number of mussel shells or living mussels in test habitats was the same as the number of mussel shells in the reference habitat. The 5 treatments were chosen to measure the attractiveness of factors that might influence the amphipods in their natural lake environment. Mussels shells acted as a control, and bare tile tested the habitat effect caused by the mussel shells. The remaining 3 treatments specified the biotic influences of the zebra mussel, i.e., the presence of living mussels without biodeposited material and the availability of different food sources. Each treatment was replicated $8 \times$, except for treatments 1,2 , and 3 for G. roeselii, which were replicated 16×. The higher number of replicates in these 3 treatments was necessary for better precision. All habitat-choice experiments were conduced in a period of $1.5 \mathrm{mo}$ in August and September 2006. Four replicates from 2 different treatments (8 replicates in all) were run at the same time. Food treatments $(4,5)$ of each amphipod species were done within a single 1-wk period.

Mussels were measured with a digital sliding calliper (Preisser; Digi-Met, Gammertingen, Germany) to the nearest $0.01 \mathrm{~mm}$. The mean length of empty 


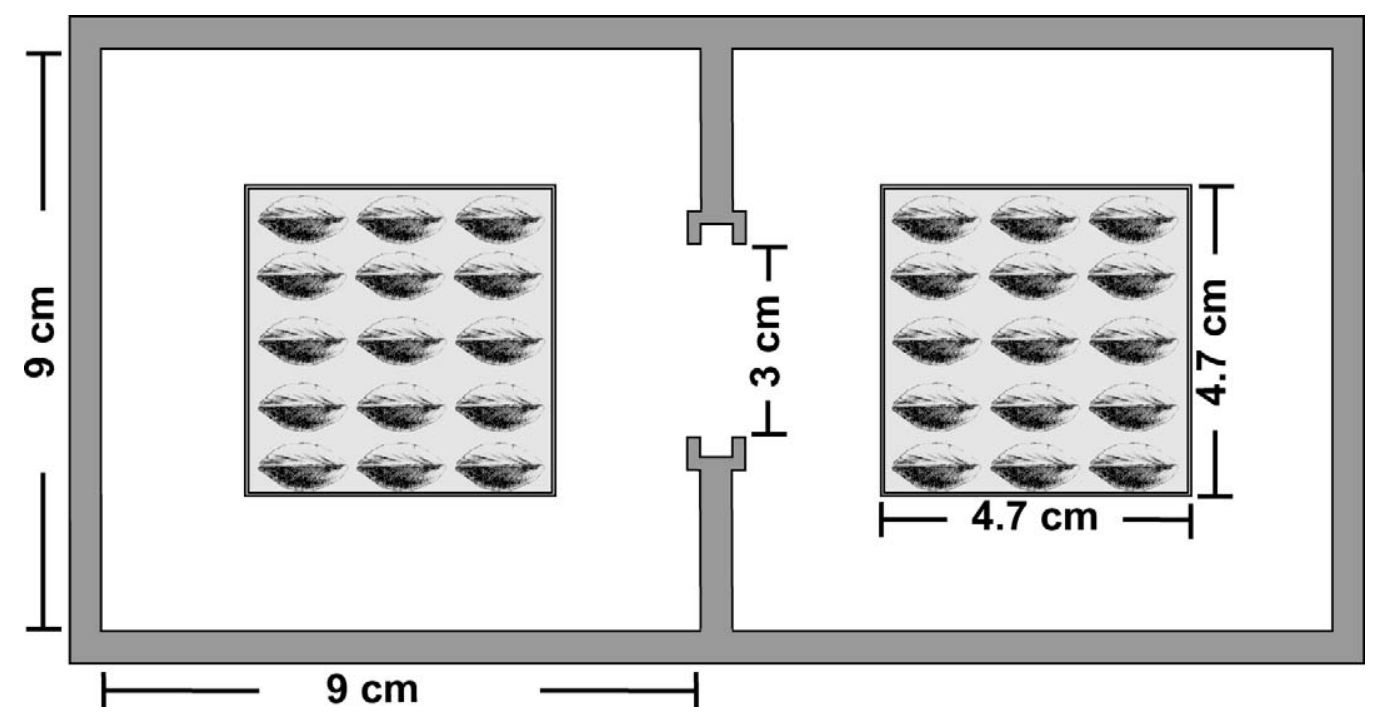

FIG. 1. Diagram of the arena used in the 2-chamber habitat-choice experiment. The passage between the chambers was closed with a removable dividing wall during the set-up phase of each trial. A tile was placed into a notch in each chamber. Fifteen mussels shells (MS) were glued to the surface of the reference tile in 1 chamber. One of 5 habitat treatments (MS, bare tile, living mussels, MS plus biodeposited material, or MS plus biodeposited material and chironomids) was presented on the surface of the tile in the $2^{\text {nd }}$ chamber.

mussel shells and living mussels was $14.99 \pm 0.46 \mathrm{~mm}$ and $14.95 \pm 0.49 \mathrm{~mm}$, respectively. Shell length did not differ significantly between the empty mussel shells and living mussels (Mann-Whitney $U$-test, $p=0.31$ ). The mussel shells and the living mussels were cleaned before use in the experiments.

Biodeposited material was collected in the lake using modified sediment traps. The sediment trap consisted of a tube of gray PVC (50-cm length; $10-\mathrm{cm}$ diameter). A funnel and a 200-mL polyethylene terephthalate (PET) flask were fixed at the lower end of the tube to collect the settling sediment. A clamp was used to hold 2 tiles $(4.7 \times 4.7 \mathrm{~cm})$ with 15 living mussels (14.91 \pm 0.48 -mm shell length) each in a vertical position above the upper opening of the sediment trap. Biodeposited material was collected twice between the end of August and the beginning of September 2006. Five traps were suspended at a depth of $2 \mathrm{~m}$ from a pontoon in the pelagic zone of Lake Constance for $7 \mathrm{~d}$. The collected material was centrifuged $(1180 \times g, 6 \mathrm{~min})$, and the supernatant was replaced with enough pure water to bring the volume to $100 \mathrm{~mL}$. Biodeposited material was stored at $4^{\circ} \mathrm{C}$ in darkness. Ash-free dry mass (AFDM) of biodeposited material was determined on an aliquot of this material (combustion at $550^{\circ} \mathrm{C}, 8 \mathrm{~h}$ ). An amount of biodeposited material equivalent to $8.0 \pm 0.9-\mathrm{mg}$ AFDM was added to the tile of one chamber in each replicate of the treatments with added biodeposited material of the habitat-choice experiment.
All animals were starved for $24 \mathrm{~h}$ over a mesh (1mm-mesh size) before the test to allow them to empty their guts. Thus, the presence of feces in a chamber indicated food uptake by the amphipods during the test. Each replicate in all tests consisted of a single arena separated by the dividing wall into 2 chambers, each of which had 1 tile of the appropriate treatment and 0.5-L aerated lake water prefiltered through a 0.45 $\mu \mathrm{m}$ filter to prevent biodeposition by zebra mussels during the test. The treatments were randomly assigned to the left or right chamber. Arenas were set up with the dividing wall in place. Ten amphipods of one species were added to each chamber (20 amphipods of the same species per replicate). This quantity of amphipods was equivalent to a density of $\sim 1200$ individuals (ind.) $/ \mathrm{m}^{2}$, which is slightly higher than natural densities (Mörtl et al. 2005). To avoid stress for the amphipods, the experimental arena was shaded by a black curtain. Thirty minutes after the amphipods were added to the chambers, the dividing wall was removed. After $24 \mathrm{~h}$, the dividing wall was re-inserted to inhibit crossing to the other chamber. The amphipods in each chamber were counted after the dividing wall was inserted.

\section{Y-maze experiment}

In September 2006, the influence of zebra mussel kairomones on both amphipod species was tested in a $y$-shaped flow-through system according to the protocol of Baumgärtner et al. (2002, 2003). The y-maze 
(length $\times$ width of root: $36 \times 13 \mathrm{~cm}$, and of each $y$-arm: $30 \times 9 \mathrm{~cm}$ ) consisted of gray PVC. Similar to the setup in Baumgärtner et al. (2002, 2003), the y-maze was shielded from the light in the climate chamber by a black curtain and was dimly illuminated with 2 fluorescent lamps (Osram Lumilux Plus, 18 W; Osram, München, Germany). Inflow of water took place near the surface at the ends of both y-arms. The outflow at the end of the mixing zone was covered by a 1-mm net so that animals could not drift away. Inflow was provided from 2 basins with taps, and the inflow volume was adjusted to $0.5 \mathrm{~L} / \mathrm{min}$ for each y-arm. In each replicate, $30-\mu \mathrm{m}$-filtered and aerated lake water was used as a reference. Fresh kairomone water was prepared on every experimental day by holding 1000 zebra mussels from a natural population $(13.2 \pm 1.6$ $\mathrm{mm}$ in length) of zebra mussels in $60 \mathrm{~L}$ of lake water for $24 \mathrm{~h}$. The conditioned water was purified through a $30-\mu \mathrm{m}$-size filter to remove potential food for the amphipods before it was used in the experiment.

At the beginning of each trial, the y-maze was filled with reference water, and the inflow was adjusted. After $1 \mathrm{~min}$ of preflow time, 20 individuals of one amphipod species were placed in the mixing zone near the outlet of the y-maze. Each replicate test lasted 30 min, and the number of the amphipods in each y-arm was determined every $2 \mathrm{~min}$. Only the values from minute 10 to minute 30 , the period when water in the root of the y-maze was fully mixed (Baumgärtner et al. 2002), were included in our calculations. Reference water was tested against reference water as a control to demonstrate that neither arm of the y-maze was preferred by the amphipods. The order of the replicates was random, and treated water and reference water were alternated between the y-arms for every replicate. Both treatments (control and kairomone water) were repeated $8 \times$.

\section{Statistical analysis}

Habitat-choice experiment.-Some animals died during the habitat-choice experiments. Therefore, the difference in the number of amphipods in the test and in reference habitats relative to the number of amphipods in the reference habitat (\% difference) at the end of the experiment was the dependent variable in the analysis. Percentages rather than actual counts were used so that replicates in which amphipods died during the experiment could be included in the analysis without introducing bias. Percent difference described the preference of amphipods for the test habitat treatment. The strength of the influence of the test habitat was assessed by ignoring the direction of habitat choice and comparing the absolute value of the
$\%$ difference to 0 (equal numbers on both habitats). Percentages were arcsine $(\sqrt{ } x)$-transformed to satisfy assumptions of normal distribution and homogeneity of the variances (Underwood 2006). Homogeneity of variances was tested with a Levene test. Differences in preference of a single species between habitat treatments were evaluated using a 1-way analysis of variance (ANOVA) with subsequent Tukey's Honestly Significant Difference (HSD) post-hoc tests. Differences between species were evaluated using a 2-way ANOVA.

Y-maze experiment.-No animals died during these experiments. Therefore, the difference in the number of individuals between the $2 \mathrm{y}$-arms at each time point was used as the dependent variable in the analysis. Homogeneity of variances was tested with a Levene test. Differences in preference between species and kairomone treatments were analyzed with a repeatedmeasures ANOVA (rm-ANOVA). All analyses were done with Statistica software (version 6.1; StatSoft Inc., Tulsa, Oklahoma) as described in Baumgärtner et al. (2002, 2003).

\section{Results}

\section{Habitat-choice experiment}

Habitat preferences differed significantly between species (2-way ANOVA, $p=0.048$; Table 1 ). However, the species $\times$ habitat interaction term was not significant $(p=0.13)$. Preferences of $G$. roeselii differed significantly among the 5 treatments (ANOVA, $p=$ 0.002; Table 1). Amphipods were equally distributed when reference habitat and mussel shells and when reference habitat and living mussels were compared (Fig. 2A). Preferences for mussel shells and living mussels over reference habitat did not differ significantly from preferences for bare tile or biodeposited material with or without chironomids over reference habitat. Preferences for biodeposited material and biodeposited material with chironomids over reference habitat were significantly greater than preferences for reference habitat over bare tile (no food). The color of feces of G. roeselii was similar to that of the food offered, indicating that amphipods ate the biodeposited material.

Preferences of $D$. villosus also differed significantly among the 5 habitat treatments (ANOVA, $p<0.001$; Table 1). Amphipods were equally distributed when reference habitat and mussel shells and when reference habitat and biodeposited material were compared (Fig. 2B). Amphipods preferred reference habitat over bare tile. Preferences for reference habitat over living mussels and preferences for mussel shells and biodeposited material over reference habitat were not 
TABLE 1. Analysis of variance results comparing responses to habitat treatments of 2 amphipod species, Gammarus roeselii and Dikerogammarus villosus, in the habitat-choice experiment. The dependent variable, \% difference, was calculated between pairwise combinations of habitats on reference (15 mussel shell [MS]) and test (MS, bare tile, living mussels, MS with biodeposited material, or MS with biodeposited material and chironomids) tiles in 2-chamber arenas.

\begin{tabular}{llrrr}
\hline \hline \multicolumn{1}{c}{ Factor } & Species & \multicolumn{1}{c}{$F$} & df & \multicolumn{1}{c}{$p$} \\
\hline Habitat & Both & 15.893 & 4 & $<0.001$ \\
Habitat & G. roeselii & 4.757 & 4 & 0.002 \\
Habitat & D. villosus & 13.260 & 4 & $<0.001$ \\
Species & Both & 4.030 & 1 & 0.048 \\
Species $\times$ habitat & Both & 1.826 & 4 & 0.13 \\
\hline
\end{tabular}

significantly different, and preferences for biodeposited material with and without chironomids over reference habitat were not significantly different. Preference for biodeposited material with chironomids over reference habitat was significantly greater than preference for reference habitat over living mussels and bare tile. Only a few $D$. villosus feces matched the color of the biodeposited material, indicating that amphipods ate little biodeposited material.

The bare tile treatment had a significantly stronger effect than the other treatments on the distribution of D. villosus (ANOVA, $F=9.159, p<0.001$ ). Treatment effects on $G$. roeselii differed significantly (ANOVA, $F=$ $2.829, p=0.032)$, but the Tukey HSD post-hoc test did not identify a specific treatment that differed significantly from the others. However, the effect of the bare tile treatment appeared to be stronger than the effect of other treatments because the bare tile effect did not differ between amphipod species (ANOVA, $F=3.679$, $p=0.105)$, and the bare tile treatment did affect $D$. villosus significantly.

\section{Y-maze experiment}

The habitat-choice experiments revealed no preference for living mussels (G. roeseli; Fig. 2A) or avoidance of living mussels (D. villosus; Fig. 2B), but the elicitor of the avoidance reaction was unknown. The y-maze experiment tested whether kairomone produced by the zebra mussels was a possible elicitor. The presence of kairomones in water elicited significant negative responses from both amphipod species (Fig. 3A, B). The mean difference in abundance of individuals between y-maze arms with reference and kairomone water was $16.2 \pm 4.3 \%$ for G. roeselii (rmANOVA, $p<0.001)$ and $10.4 \pm 3.1 \%$ for $D$. villosus (rm-ANOVA, $p<0.01)$.

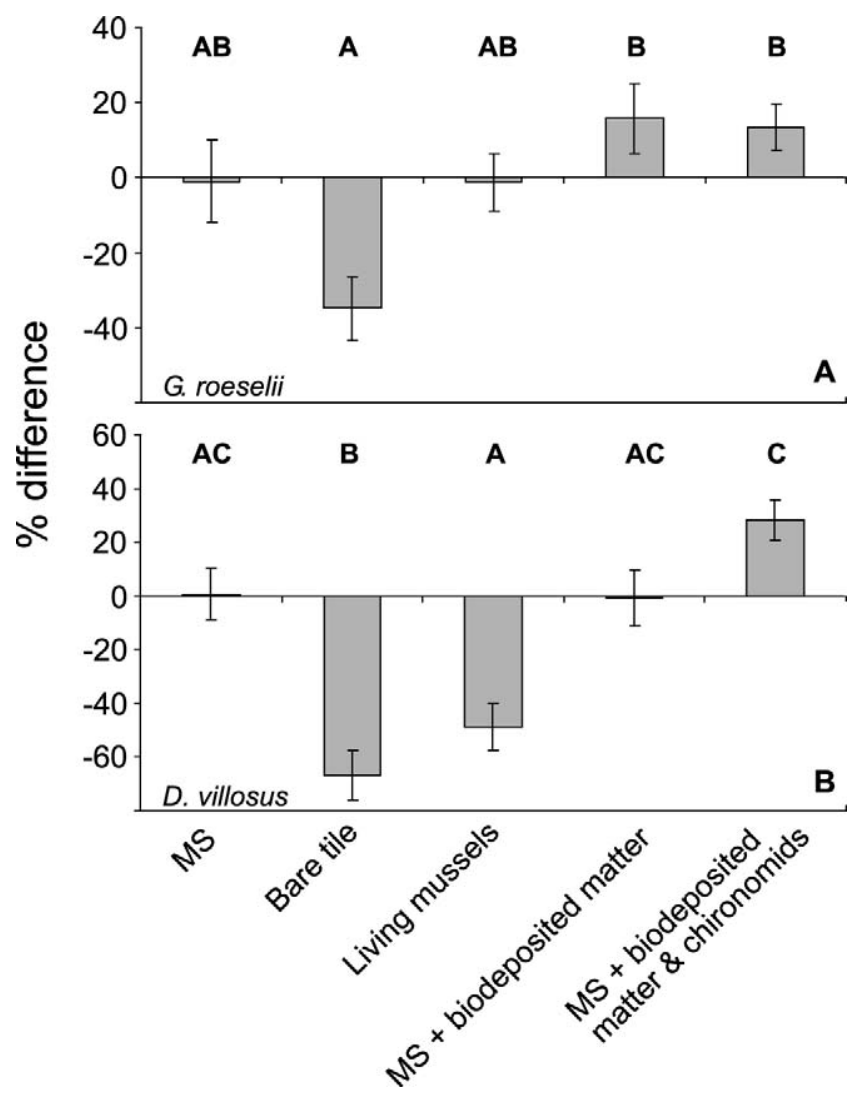

FIG. 2. Mean $\%$ difference ( \pm 1 SE) of Gammarus roeselii (A) and Dikerogammarus villosus (B) for habitats in pairwise choice experiments comparing responses to 1 of 5 test habitat treatments (mussel shells [MS], bare tile, living mussels, MS plus biodeposited material from zebra mussels, and MS plus biodeposited material and 30 living chironomids) against a reference habitat (MS). Percent difference was calculated based on the distribution of amphipods at the end of the experiment. Negative values indicate a preference for the reference habitat; positive values indicate a preference for the test habitat. Bars with the same uppercase letter are not significantly different $(p>0.05)$.

\section{Discussion}

Zebra mussels increase the amount of benthic organic matter by filtration and biodeposition (e.g., Stanczykowska et al. 1976, Klerks et al. 1996, Ricciardi et al. 1997, Stewart et al. 1998). Benthic organic matter is an appropriate food source for detritivores and omnivores, and its increase often is hypothesized to be the direct biotic factor that causes abundances of detritivores and omnivores to increase in habitats that have been invaded by zebra mussels. Moreover, predators might benefit indirectly from organic matter deposition if it increases the abundance of detritivores, such as chironomids. Zebra mussels also increase the structural complexity of benthic habitats, and the additional structure is hypothesized to be an abiotic 


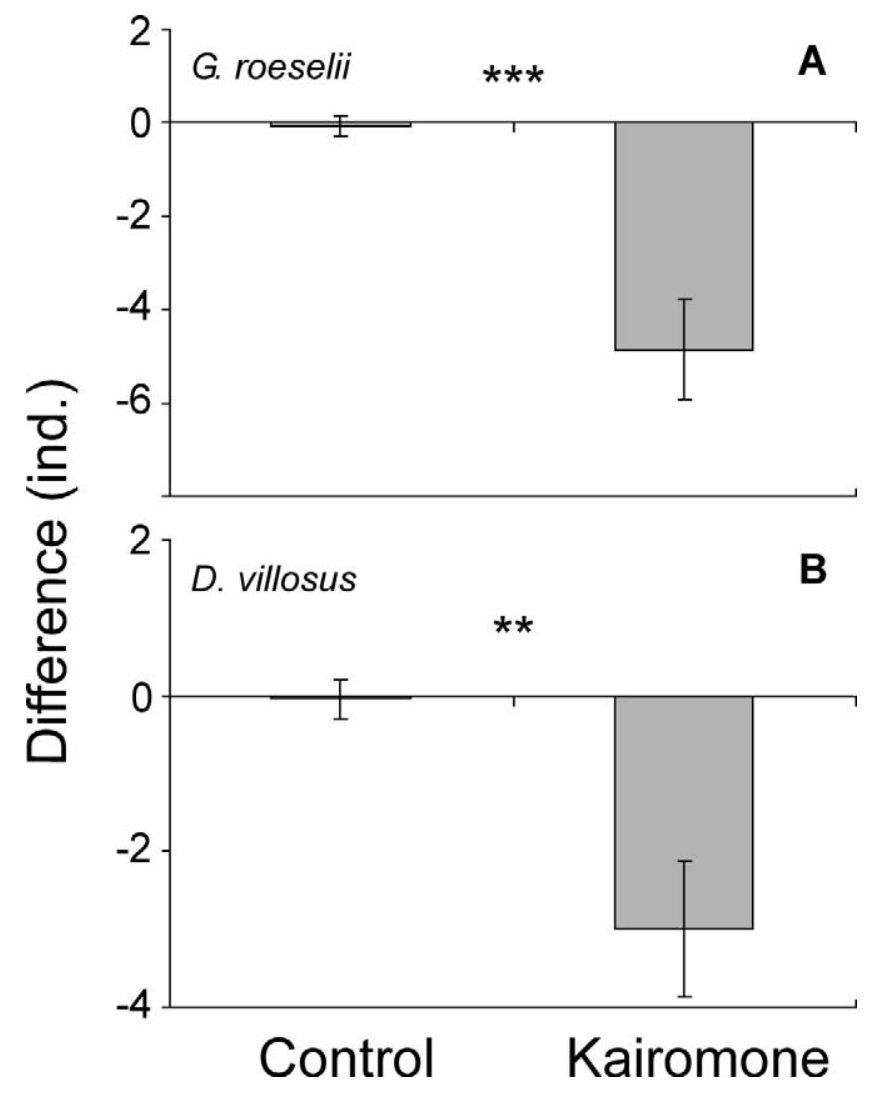

FIG. 3. Mean $( \pm 1$ SE) difference in the number of individuals (ind.) of Gammarus roeselii (A) and Dikerogammarus villosus (B) in 2 arms of a y-maze experiment testing responses to lake water conditioned with zebra mussels, i.e., containing kairomones, and unconditioned water. Values are the difference in the number of individuals between the arms of the y-maze, averaged at 10-min intervals from 10 to 30 min after initiating the experiment. Positive values indicate preference for the conditioned water; negative values indicate avoidance of the conditioned water. ${ }^{* *} p<0.01$, *** $p<0.001$.

factor that causes abundances of benthic invertebrates to increase in habitats that have been invaded by zebra mussels. Our results support both of these hypotheses and indicate that the native G. roeselii and invasive $D$. villosus both responded (either directly or indirectly) to the increased food supply associated with biodeposited material in Lake Constance. Therefore, the biodeposition of invading zebra mussels could lead to the formation of new food webs and increase secondary production in benthic systems.

The 2 species differed significantly in their habitat preferences (Table 1), which indicated different responses to food sources. Gammarus roeselii responded positively to the structure associated with mussel shells and to any additional food source (biodeposited material with or without chironomids), as was evident from the feces at the end of the experiment. However, our data did not provide evidence that G. roeselii actually fed on chironomids. Moreover, chironomids were added only in combination with the biodeposited material, so a true preference for one food source over the other could not be determined. On the other hand, $D$. villosus responded positively to biodeposited material with chironomids but not to biodeposited material without chironomids. These results agree with the known feeding strategies of both amphipod species. Dikerogammarus villosus is a predator (Dick et al. 2002), and Gammarus is a shredder or omnivore (Bärlocher and Kendrick 1973, Pöckl 1992, 1993, Friberg and Jacobsen 1994).

Both species avoided bare tile. The response of $D$. villosus to bare tile was significantly stronger than its response to any other habitat treatment, and the response of $G$. roeselii to bare tile tended to be stronger than its response to any other treatment. Thus, the high structural complexity provided by the mussel shells was a clear driver of habitat choice for both species. This strong response might be associated with reduced predation risk with increasing habitat complexity (González and Downing 1999). It is not specific to amphipods, and the potential explanation can be applied to most benthic macroinvertebrates (Stewart et al. 1998).

Both amphipods species showed a significant negative response to lake water conditioned with zebra mussels in the y-maze experiments. Dikerogammarus villosus also avoided tiles with living mussels in the habitat-choice experiment. These results indicate that kairomones released by living zebra mussels cannot explain the increase in abundance of amphipods in the field and that kairomones might actually provoke an avoidance reaction. Zebra mussels excrete $\mathrm{NH}_{4}{ }^{+}$as an end product of their metabolism, and $\mathrm{NH}_{4}{ }^{+}$accumulates in the surrounding water (Heath et al. 1995). Amphipods are very sensitive to $\mathrm{NH}_{4}{ }^{+}$ contamination, which can be lethal at high concentrations (Williams et al. 1986, Berenzen et al. 2001). Thus, the amphipods in our experiments might have avoided living mussels because of $\mathrm{NH}_{4}^{+}$accumulation in the chamber.

\section{Implications for the benthic community}

Our experiments were carried out under standardized laboratory conditions and cannot reproduce the variability of environmental conditions in the lake. Under natural conditions, the habitat preference of amphipods varies seasonally, and high-complexity substrates are not preferred over low-complexity substrates throughout the year (González and Down- 
ing 1999). Living mussels are preferred by gammarids only in late summer, possibly because late-summer peaks in phytoplankton concentrations cause maximum biodeposition by zebra mussels and high food availability (Reeders and Bij de Vaate 1992). During winter and spring, abundances of zebra mussels are low in Lake Constance because of predation by diving ducks (Werner et al. 2005). Thus, structural complexity and biodeposition vary seasonally, and both are less important in winter and spring than in summer and autumn. The abundances of amphipods also are lowest during winter (Mörtl et al. 2005). Mörtl and Rothhaupt (2003) observed an increase in abundance of $G$. roeselii and chironomids on zebra mussels in July 1999, during a period when habitat complexity and biodeposition rate presumably were high. Our results suggest that this increase might be attributable to the structural complexity and additional food source from biodeposition by zebra mussels.

In Lake Constance, the benthic food web has been disturbed by the Ponto Caspian invader D. villosus, which has colonized the lake rapidly since 2002 (Mörtl et al. 2005). One consistent response in many freshwater systems during the establishment of $D$. villosus is the decline or extirpation of native amphipods because of predation by D. villosus (Ponyi 1956, Dick and Platvoet 2000, Kinzler and Maier 2003, Josens et al. 2005). Other benthic macroinvertebrates are also prey of $D$. villosus, and their abundances decrease after its invasion (Dick et al. 2002, Krisp and Maier 2005).

In conclusion, our results provide strong indications that amphipods are involved in a Dreissena-biodepositbased food web. To our knowledge, ours is the first study that indicates how biodeposition by zebra mussels might influence habitat choice by benthic macroinvertebrates. The effects of zebra mussels on amphipods differ between species. Omnivorous $G$. roeselii was attracted to biodeposited material and to mussel shells, whereas the predatory invader $D$. villosus was attracted to shells only when added animal prey was present. Therefore, the invasive amphipod species is influenced indirectly by zebra mussels through their effect on other species that feed on biodeposited material. The other species involved in this possible food web and the ways in which they are influenced by invading species, such as $D$. villosus, remain to be clarified.

\section{Acknowledgements}

Markus Döpfner and Matthias Geiger tested and established the method of the habitat-choice experiment, and Ulrike Koch provided advice with the ymaze. Special thanks are due André Gergs, Almut
Hanselmann, and Stefan Werner for their comments on an earlier version of the manuscript and Karen A. Brune for editing the English of the manuscript. We thank 2 anonymous referees for their helpful comments on the manuscript. This work was supported by the DFG (German Research Foundation) within the collaborative research centre SFB 454 Littoral of Lake Constance.

\section{Literature Cited}

Bärlocher, F., AND B. Kendrick. 1973. Fungi and food preferences of Gammarus pseudolimnaeus. Archiv für Hydrobiologie 72:501-516.

BAumgärtner, D., A. D. JungBluth, U. KoCh, AND E. von Elert. 2002. Effects of infochemicals on microhabitat choice by the freshwater amphipod Gammarus roeseli. Archiv für Hydrobiologie 155:353-367.

Baumgärtner, D., U. Koch, and K. O. Rothhaupt. 2003. Alteration of kairomone-induced antipredator response of the freshwater amphipod Gammarus roeseli by sediment type. Journal of Chemical Ecology 29:1391-1401.

BerenZEN, N., R. Schulz, AND M. Liess. 2001. Effects of chronic ammonium and nitrite contamination on the macroinvertebrate community in running water microcosms. Water Research 35:3478-3482.

Cleven, E. J., ANd P. Frenzel. 1993. Population dynamics and production of Dreissena polymorpha (Pallas) in River Seerhein, the outlet of Lake Constance (Obersee). Archiv für Hydrobiologie 127:395-407.

Dick, J. T. A., AND D. Platvoet. 2000. Invading predatory crustacean Dikerogammarus villosus eliminates both native and exotic species. Proceedings of the Royal Society of London Series B: Biological Sciences 267:977-983.

Dick, J. T. A., D. Platvoet, and D. W. Kelly. 2002. Predatory impact of the freshwater invader Dikerogammarus villosus (Crustacea:Amphipoda). Canadian Journal of Fisheries and Aquatic Sciences 59:1078-1084.

FRIBERG, N., AND D. JACOBSEN. 1994. Feeding plasticity of two detritivore-shredders. Freshwater Biology 32:133-142.

GonZÁlez, M. J., AND A. Downing. 1999. Mechanisms underlying amphipod responses to zebra mussel (Dreissena polymorpha) invasion and implications for fishamphipod interactions. Canadian Journal of Fisheries and Aquatic Sciences 56:679-685.

GRIFFITHS, R. W. 1993. Effects of zebra mussels (Dreissena polymorpha) on the benthic fauna of Lake St. Clair. Pages 415-437 in T. F. Nalepa and D. W. Schloesser (editor). Zebra mussels: biology, impacts, and control. Lewis Publishers, Boca Raton, Florida.

Heath, R. T., G. L. Fahnenstiel, W. S. Gardner, J. F. Cavaletto, AND S. J. HwANG. 1995. Ecosystem-level effects of zebra mussel (Dreissena polymorpha): an enclosure experiment in Saginaw Bay, Lake Huron. Journal of Great Lakes Research 21:501-516.

Holland, R. E. 1993. Changes in the planktonic diatoms and water transparency in Hatchery Bay, Bass Island Area, 
western Lake Erie, since the establishment of the zebra mussel. Journal of Great Lakes Research 19:617-624.

IGKB (INTERNATIONALE GEWÄSSERSCHUTZKOMMISSION FÜR DEN BODENSEE). 2004. Der Bodensee Zustand-Fakten-Perspektiven. Internationale Gewässerschutzkommission für den Bodensee, Stuttgart, Germany. (Available from: www.igkb.de)

Josens, G., A. Bij de Vaate, P. Usseglio-Polatera, R. Cammaerts, F. Cherot, F. Grisez, P. Verboonen, and J.-P. VANDEn Bossche. 2005. Native and exotic Amphipoda and other Peracarida in the River Meuse. Hydrobiologia 542:203-220.

KinZleR, W., AND G. MAIER. 2003. Asymmetry in mutual predation: possible reason for the replacement of native gammarids by invasives. Archiv für Hydrobiologie 157: 473-481.

KleRks, P. L., P. C. Fraleigh, AND J. E. LawniczaK. 1996. Effects of zebra mussel (Dreissena polymorpha) on seston levels and sediment deposition in western Lake Erie. Canadian Journal of Fisheries and Aquatic Sciences 53:2284-2291.

KRISP, H., AND G. MAIER. 2005. Consumption of macroinvertebrates by invasive and native gammarids: a comparison. Journal of Limnology 64:1-5.

Mitchell, J., E. L. Mills, N. IdRISI, AND R. Michener. 1996. Stable isotopes of nitrogen and carbon in an aquatic food web recently invaded by Dreissena polymorpha (Pallas). Canadian Journal of Fisheries and Aquatic Sciences 53: 1445-1450.

MörTL, M. 2003. Biotic interactions in the infralittoral of Lake Constance. PhD Thesis, University of Constance, Constance, Germany.

Mörtl, M., U. Mürle, J. Ortlepr, P. Rey, N. Scheifhacken, and S. WeRnER. 2005. Dikerogammarus villosus (Crustacea:Amphipoda) und Corbicula fluminea (Bivalvia:Veneroidea) im Bodensee. Pages 15-30 in L. f. U. Baden-Württemberg (editor). Wirbellose Neozoen im Bodensee. Landesanstalt für Umweltschutz Baden-Württemberg, Institut für Seenforschung, Karlsruhe, Germany.

Mörtl, M., And K. O. RothHaupt. 2003. Effects of adult Dreissena polymorpha on settling juveniles and associated macroinvertebrates. International Review of Hydrobiology 88:561-569.

Mürle, U., A. BeCKer, AND P. Rey. 2004. Dikerogammarus villosus (Amphipoda) new in Lake Constance. Lauterbornia 49:77-79.

Nicholls, K. H., and G. J. Hopkins. 1993. Recent changes in Lake Erie (north shore) phytoplankton: cumulative impacts of phosphorus loading reductions and the zebra mussel introduction. Journal of Great Lakes Research 19: 637-647.

PöcKL, M. 1992. Effects of temperature, age and body size on moulting and growth in the freshwater amphipoda Gammarus fossarum and G. roeseli. Freshwater Biology 27:211-225.

PöCKL, M. 1993. Reproductive potential and lifetime potential fecundity of the freshwater amphipods Gammarus fossarum and G. roeseli in Austrian streams and rivers. Freshwater Biology 30:73-91.
PONYI, E. 1956. Ökologische, ernährungsbiologische und systematische Untersuchungen an verschiedenen Gammarus-Arten. Archiv für Hydrobiologie 52:367-387.

ReEders, H. H., AND A. BiJ DE VAATE. 1992. Bioprocessing of polluted suspended matter from the water column by the zebra mussel (Dreissena polymorpha Pallas). Hydrobiologia 239:53-63.

Ricciardi, A., F. G. Whoriskey, And J. B. Rasmussen. 1997. The role of the zebra mussel (Dreissena polymorpha) in structuring macroinvertebrate communities on hard substrata. Canadian Journal of Fisheries and Aquatic Sciences 54:2596-2608.

Roditi, H. A., D. L. Strayer, and S. E. G. Findlay. 1997. Characteristics of zebra mussel (Dreissena polymorpha) biodeposits in a tidal freshwater estuary. Archiv für Hydrobiologie 140:207-219.

Silver Botts, P., B. A. Patterson, And D. W. Schloesser. 1996. Zebra mussel effects on benthic invertebrates: physical or biotic? Journal of the North American Benthological Society 15:179-184.

Skubinna, J. P., T. G. CoOn, And T. R. Batterson. 1995. Increased abundance and depth of submersed macrophytes in response to decreased turbidity in Saginaw Bay, Lake Huron. Journal of Great Lakes Research 21: 476-488.

StANCZYKOWSKA, A., W. LaWACZ, J. MatTice, AND K. LeWANDOWSKI. 1976. Bivalves as a factor affecting circulation of matter in Lake Mikolajskie (Poland). Limnologica 10: 347-352.

Stewart, T. W., AND J. M. HAYnes. 1994. Benthic macroinvertebrate communities of southwestern Lake Ontario following invasion of Dreissena. Journal of Great Lakes Research 20:479-493.

Stewart, T. W., J. G. Miner, And R. L. Lowe. 1998. Quantifying mechanisms for zebra mussel effects on benthic macroinvertebrates: organic matter production and shellgenerated habitat. Journal of the North American Benthological Society 17:81-94.

UNDERWOOD, A. J. 2006. Experiments in ecology: their logical design and interpretation using analysis of variance. Cambridge University Press, Cambridge, UK.

Walz, N. 1978. Die Produktion der Dreissena-Population und deren Bedeutung im Stoffkreislauf des Bodensees. Archiv für Hydrobiologie 82:482-499.

Werner, S., M. Mörtl, H. G. Bauer, and K. O. Rothhaupt. 2005. Strong impact of wintering waterbirds on zebra mussel (Dreissena polymorpha) populations at Lake Constance, Germany. Freshwater Biology 50:1412-1426.

Williams, K. A., D. W. J. Green, AND D. Pascoe. 1986. Studies on the acute toxicity of pollutants to freshwater macroinvertebrates. Archiv für Hydrobiologie 106:61-70.

Wudkevich, K., B. D. Wisenden, D. P. Chivers, and R. J. F. SмIтH. 1997. Reactions of Gammarus lacustris to chemical stimuli from natural predators and injured conspecifics. Journal of Chemical Ecology 23:1163-1173. 